\title{
Looking back to 50 years of a surgeon's career: combining assistance, education, and research
}

\author{
Jean-Yves Petit ${ }^{1}$ (D), Cicero Urban² (D)
}

A long time ago, I was sixteen and wanted to be an artist, a painter.

My father was a doctor, he wanted me to become a doctor, a surgeon like his father... He wanted to put me on the right family track! I did not resist so much. Being a surgeon was a prestigious job, in my opinion.

I was not the kind of intellectual nor very fond of reading books. I got my degrees working moderately at the university, impatient to become a surgical resident, despite the difficulty and the hard selection of the competitive examination.

As soon as I could start working at the hospital, I knew that my choice for this profession was right. Besides that, to confirm my likelihood of learning with practice more than with books, I remember learning my first surgical knowledge mostly in the operating room more than in the library.

What kinds of surgery? During my residency training, I experienced several specialties, such as visceral, cervico-facial, orthopedic... and, finally, plastic surgery. I was not interested

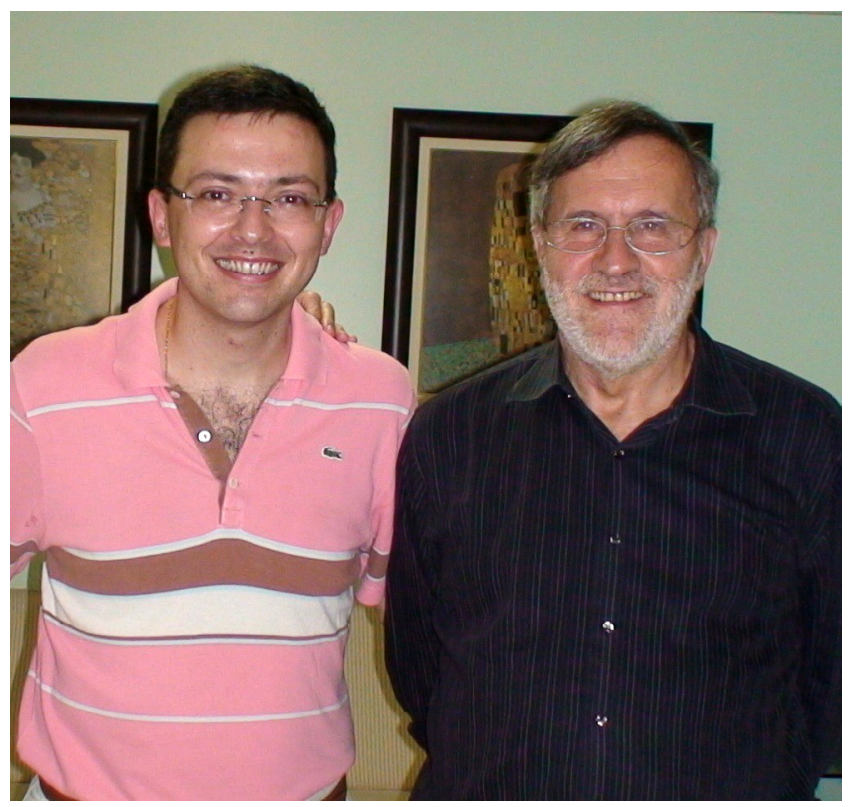

in the kind of patients usually looking for esthetic surgery as well as private practice, which is mostly performed in this specialty. I was mainly trained in a cancer institute (Gustave Roussy Cancer Institute), where I also acquired my competence in plastic surgery. In Gustave Roussy, I got the position of Head of the Department of Breast Cancer, including breast reconstructions and skin cancer treatments.

At this point of my surgical status, I should add a comment about this period of my life, which influenced my thoughts about society. First, I started to raise questions when I came back from a trip to China in 1966. Then, when I was chief resident in Gustave-Roussy Cancer Institute, the political events of 1968 were happening everywhere in France, and noisy demonstrations were surrounding the hospital. I could not help but being strongly committed to these events. I participated in a group whose purpose was to question the abuse of medical power over patients. We wanted to help patients to know more about their disease, and better understand and accept the type of surgical treatment required. Moreover, I participated as a committed fighter in favor of abortion freedom, as well as for the women's lib movement.

Coming back to my activities at Gustave Roussy Cancer Institute, I took the opportunity of combining my competence on both reconstructive surgery and breast surgery to develop the breast reconstructive activity. In 1975, it was the very beginning of breast reconstruction. The first trials of breast conserving surgery in breast cancer were just starting. Mastectomy was still the usual treatment. Therefore, the patients had a new demand for psychologic improvement after mastectomy. I started to perform reconstructions with silicone implants (already used at this time, in 1975, for esthetic surgery), keeping indications only for good prognostic patients, such as in situ cancers with at least several years of follow up without recurrences. Radiotherapy was also indicated, sometimes providing poor local tissue conditions. In the late seventies, John Bostwick proposed the use of a muscular flap: the latissimus dorsi transposition with an island of skin paddle to replace the radiated tissue. Several years

${ }^{1}$ Plastic Surgery Department, European Institute of Oncology - Milan, Italy.

${ }^{2}$ Breast Unit, Hospital Nossa Senhora das Graças - Curitiba (PR), Brazil.

*Corresponding author: cicerourban@hotmail.com

Conflict of interests: nothing to declare.

Received on: 06/01/2020. Accepted on: 06/02/2020 
later, Carl Hartrampf invented the TRAM flap reconstruction. I went to Atlanta to learn the technique. Carl was a very nice person and invited me to stay in the OR during his operation. Incidentally, we were two privileged surgeons to stay in the OR behind the camera for the video transmission to the course. Back then, my English was not so fluent and, when discussing with the other invited surgeon after not having understood his name, I was asking him where he was from, what was his position in LA, trying to be polite... and, finally, what was his name? He was Mac Kissok! One of the most famous plastic surgeons, the father of the worldwide well-known technique of reduction mammoplasty. Imagine how stupid I felt!

At Gustave Roussy Institute, the results of our trial on conservative treatment allowed us to include the technique in our protocol of breast cancer treatment in small tumors. In the early eighties, I started to propose techniques of oncoplastic for partial breast reconstruction with poor cosmetic results. It is interesting to show that progress in surgery can result from a combination of different specialties. Although extreme specialization should be required in microsurgical techniques, for instance, improvement of psychological results in breast cancer treatment could be obtained with the association of general cancer surgery and plastic surgery techniques.

Likewise, working in a cancer team was familiar to me as to the role of statistics to evaluate any kind of results. It helped me to write papers with more reliable results than those produced by pure plastic surgeons.

In October 1994, I got the opportunity to move to the European Institute of Oncology (EIO), a new cancer institute of Umberto Veronesi, in Milan. He took me on to become Head of the Plastic Surgery Department of the brand-new hospital, which had been open for two months only!

It was not so easy to change all my habits of daily work, especially with my very poor Italian. But there was great enthusiasm among all the new teams coming from different countries. We aimed to build a truly international institute.

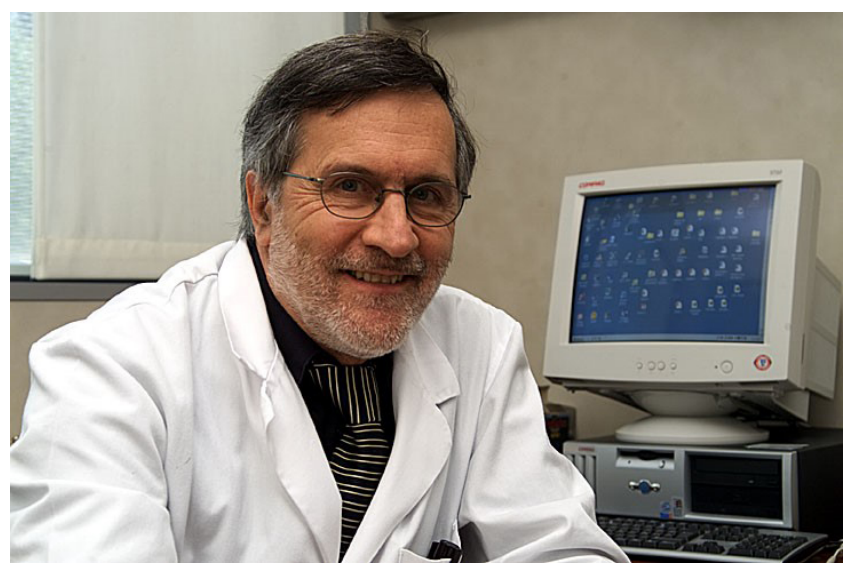

I brought along my young Brazilian assistant, Mario Rietjens, who was working with me in Paris for many years. He truly helped me raise our new team. Then, we took on Cristina Garusi, a young Italian plastic surgeon. Mario and I were both trained in in general and plastic surgery. The team grew slowly with the inclusion of Francesca De Lorenzi, who was also a pure plastic surgeon, and several other young assistants who came in.

At Gustave Roussy Institute, I was in charge of both the cancer and the reconstructive breast surgery, whereas in Milan, Veronesi asked me to limit my activity to reconstructive surgery, like it is done in the US.

I was very happy in Italy, thanks to the research dynamism implemented by Veronesi and the other teams. Among the other heads of different departments, most were internationally recognized oncologists. During the first years, we were greatly encouraged by this experience of an original European Cancer Institute. Veronesi pushed everyone to make research and publish. I did not spend so much time writing papers when I was in Paris...

Many young surgeons spent several months with us, specially to learn about immediate breast reconstruction. Among these fellows coming from abroad, one from Brazil became a big friend: Cicero Urban. He stayed almost one year (or more?) and since that time he remained in close connection both with Mario Rietjens and me. I remember the nice philosophical discussions we shared during dinner after working days. That was the start of a deep friendship between us.

It was a long time ago since I was performing immediate reconstructions in France, whereas the technique was barely known in Italy. Many patients came to the EIO to benefit from this new technique in the country $\mathrm{y}^{1-3}$.

It was also the first time that patients were offered a possibility of partial breast reconstructions ${ }^{2}$. Symmetry procedures were also proposed to improve the final psychological status of patients. In the beginning, women were often reluctant to having their virgin breasts and we obviously always let them decide, except when there was some reason to check abnormalities, such as microcalcifications in a normal breast.

Microsurgical reconstruction was also introduced later in our protocols, thanks to the nice work of Cristina Garusi. She became an important international expert in microsurgical meetings.

The last technical evolution in my department was the introduction of fat grafting, which derived from the esthetic technique of liposuction ${ }^{2}$. The technique rapidly developed, especially for conservative treatment morphology improvement, but also to improve all kinds of total breast reconstructions. Finally, our purpose was to reconstruct the breast only with a fat graft. Good results were obtained, although requiring too many operating sessions.

My question remained focused on proving the oncologic innocuity of this technique. Experimental research was made in the EIO laboratory of Francesco Bertolini. On animal experiments, 
he showed that the transposed fat was able to stimulate the growth of cancer cells and metastasis. Several clinical retrospective studies performed in our department did not confirm such recurrence risk in our patients. However, I set up a randomized trial including conservative treatment patients with immediate fat grafting to evaluate both the morphologic improvement and the cancer risk with a Chinese team two years ago, with whom I was scientifically connected for many years. The results will be available in two or three years probably².

Breast cancer treatment may no longer be invasive in the future, avoiding psychological disasters. Despite such hope, surgery remains one of the major resources against the disease, providing a higher percentage of cure when associated with other medical treatments, including radiotherapy.

\section{REFERENCES}

1. Kaur N, Petit JY, Rietjens M, Maffini F, Luini A, Gatti G, et al. Comparative study of surgical margins in oncoplastic surgery and quadrantectomy in breast cancer. Ann Surg Oncol. 2005;12(7):539-45. http://doi.org/10.1245/ASO.2005.12.046

2. Petit JY, Clough K, Sarfati I, Lohsiriwat V, de Lorenzi F, Rietjens M.Lipofilling in breast cancer patients: from surgical technique to oncologic point of view. Plast ReconstrSurg. 2010;126(5):262e3e. http://doi.org/10.1097/PRS.0b013e3181ef94a8

3. Petit JY, Veronesi U, Luini A, Orecchia R, Rey PC, Martella $\mathrm{S}$, et al. When mastectomy becomes inevitable: the nipplesparing approach. Breast. 2005;14(6):527-31. http://doi. org/10.1016/j.breast.2005.08.028 